\begin{tabular}{|c|l|}
\hline Title & Fabrication of A nodic Porous A lumina by Squaric A cid A nodizing \\
\hline Author(s) & Kikuchi, Tatsuy a; Y amamoto, T suy oshi; Natsui, Shungo; Suzuki, Ryosuke O. \\
\hline Citation & $\begin{array}{l}\text { Electrochimica A cta, 123, 14.22 } \\
\text { https://doi.org/10.1016/.electacta.2013.12.186 }\end{array}$ \\
\hline Issue Date & 201403 20 \\
\hline Doc URL & http://hdl.handle.net/2115/56406 \\
\hline Type & article (author version) \\
\hline File Information & Squaric2.pdf \\
\hline
\end{tabular}

Instructions for use 


\section{Fabrication of Anodic Porous Alumina by Squaric Acid Anodizing}

Tatsuya Kikuchi ${ }^{*}$, Tsuyoshi Yamamoto, Shungo Natsui, and Ryosuke O. Suzuki Faculty of Engineering, Hokkaido University

N13-W8, Kita-ku, Sapporo, Hokkaido, 060-8628, Japan

*Corresponding author: Tatsuya Kikuchi

TEL: +81-11-706-6340

FAX: +81-11-706-6342

E-mail: kiku@eng.hokudai.ac.jp 


\begin{abstract}
The growth behavior of anodic porous alumina formed via anodizing in a new electrolyte, squaric acid (3,4-dihydroxy-3-cyclobutene-1,2-dione), is reported for the first time. A high-purity aluminum foil was anodized in a $0.1 \mathrm{M}$ squaric acid solution at $293 \mathrm{~K}$ and a constant applied potential of 100-150 V. Anodic oxides grew on the aluminum foil at applied potentials of 100-120 V, but a burned oxide film was formed at higher voltage. Anodic porous alumina with a cell size of approximately 200-400 nm and sub-100-nm-scale pore diameter was successfully fabricated by anodizing in squaric acid. The cell size of the anodic oxide increased with anodizing time because of the uneven growth of the porous layer. The anodic porous alumina obtained by squaric acid anodizing consists of amorphous $\mathrm{Al}_{2} \mathrm{O}_{3}$ containing 5-6 at $\%$ carbon from the electrolyte.
\end{abstract}

Key words: Aluminum; Anodizing; Anodic Porous Alumina; Squaric Acid; Nanostructure fabrication 


\section{Introduction}

Porous anodic oxide films of aluminum (anodic porous alumina) have been widely investigated as nanotemplates and resist films with good insulating properties for various micro- and nano-technology applications, such as magnetic recording media [1, 2], electronic devices [3], biosensors [4], photonic crystals [5-7], microlens arrays [8, 9], plasmonic devices [10-12], three-dimensional microstructures [13-15] and other basic nanodevices [16]. When aluminum is anodized in appropriate acidic electrolytes, porous alumina develops, which exhibits a uniform array of hexagonal cells, each containing a uniform cylindrical nanopore at the center [17-22] (lower right in Fig. 1). The morphology of anodic porous alumina, especially its cell size (identical meaning to interpore distance) and pore diameter in the porous layer, is limited by the electrolyte and voltage (electrochemical potential) applied during anodizing [23, 24]. Fig. 1 summarizes the anodizing electrolytes that have been reported to date for porous alumina fabrication. Sulfuric $\left(\mathrm{H}_{2} \mathrm{SO}_{4}\right)$, oxalic $\left((\mathrm{COOH})_{2}\right)$, and phosphoric $\left(\mathrm{H}_{3} \mathrm{PO}_{4}\right)$ acids are well-known, self-ordering anodizing solutions for porous alumina fabrication, and highly ordered porous alumina can be obtained by anodizing in these solutions at constant voltages of 18-25 V, $40 \mathrm{~V}$, and 160-195 V, respectively [24-29]. Malonic acid $\left(\mathrm{HOOC}-\mathrm{CH}_{2}-\mathrm{COOH}\right)$ and tartaric acid $\left(\mathrm{HOOC}-(\mathrm{CHOH})_{2}-\mathrm{COOH}\right)$, typical dicarboxylic acids, have also been reported to support the fabrication of highly ordered porous alumina fabrication at $120 \mathrm{~V}$ and $195 \mathrm{~V}$, respectively [30, 31]. In addition, several other electrolytes, such as chromic $\left(\mathrm{H}_{2} \mathrm{CrO}_{4}\right)[32,33]$, malic $\left(\mathrm{HOOC}-\mathrm{CH}(\mathrm{OH})-\mathrm{CH}_{2}-\mathrm{COOH}\right)$ $[23,34]$, citric $\left(\mathrm{HOCO}-\mathrm{CH}_{2}-\mathrm{C}(\mathrm{OH})(\mathrm{COOH})-\mathrm{COOH}\right)$ ) [23], and glycolic $\left(\mathrm{CH}_{2} \mathrm{OH}-\mathrm{COOH}\right)$ [23] acids, have been reported as anodizing electrolytes to date. However, the formation of thick porous alumina with straight nanopores by anodizing in chromic acid is difficult because of branching and colony-forming nanopores [35]. Although citric acid anodizing has already been used for nanostructure fabrication [36], other organic electrolytes, including malic and glycolic acid solutions, cause the formation of non-uniform anodic porous alumina [23, 34]. Therefore, five self-ordering electrolytes, namely, sulfuric, oxalic, and phosphoric acids, are generally selected for anodic porous alumina fabrication by many researchers.

In recent years, new anodizing procedures using an effective experimental approach and optimal anodizing conditions have been reported by several researchers to control the nano-scale features of anodic porous alumina. Lee et al. studied the rapid formation of ordered porous alumina by a hard anodizing procedure involving a powerful cooling stage and obtained an ultra-high aspect ratio $(>1,000)$ of anodic porous alumina by anodizing in oxalic acid at 120-150 V [24]. They also reported the structural control of porous alumina by the pulse anodizing of aluminum and obtained well-defined three-dimensional nanoporous alumina membranes [26]. The fabrication of self-ordered anodic porous alumina at a previously unutilized ordering voltage was achieved by Almasi-Kashi et al. in a mixture of sulfuric and oxalic acid electrolytes [37]. The fabrication of high-aspect-ratio anodic porous alumina templates with 15 -nm nanopores 
was realized by Martin et al. by anodizing aluminum in an ethylene glycol containing sulfuric acid electrolyte [38]. However, the potential applications of anodic porous alumina are still limited by the narrow range of available electrolytes, as mentioned above. Thus, the discovery of additional electrolytes would greatly expand the applicability of anodic porous alumina. Very recently, we reported a self-ordered porous alumina formed via anodizing in a new self-ordered electrolyte, selenic acid $\left(\mathrm{H}_{2} \mathrm{SeO}_{4}\right.$, Fig. 1) [39]. Selenic acid anodizing works effectively at a previously unutilized self-ordering voltage (48 V) with $110 \mathrm{~nm}$ cell size.

In this research work, the authors report, for the first time, an anodic porous alumina formed via anodizing in a new electrolyte, squaric acid $\left(\mathrm{C}_{4} \mathrm{H}_{2} \mathrm{O}_{4}\right.$ or $\mathrm{H}_{2} \mathrm{SQ}$, 3,4-dihydroxy-3-cyclobutene-1,2-dione, Fig. 1). Squaric acid was first synthesized by Cohen, et al. in 1959 [40] and is currently the most popular cyclic oxocarbon acid. It is typically used as a bioorganic and medicinal compound formed by organic synthetic chemistry [40-44]. Squaric acid is a strong diacid that exhibits two acidic hydroxyl groups with $\mathrm{pKa}$ values of 0.5 and 3.5 [42].

$$
\begin{gathered}
\mathrm{H}_{2} \mathrm{SQ}=\mathrm{H}^{+}+\mathrm{HSQ}^{-} \quad\left(\mathrm{pKa}_{1}=0.5\right) \\
\mathrm{HSQ}^{-}=\mathrm{H}^{+}+\mathrm{SQ}^{2-} \quad\left(\mathrm{pKa}_{2}=3.5\right)
\end{gathered}
$$

It is believed that squaric acid has the potential to behave as a suitable electrolyte for anodic porous alumina fabrication because of its diacid dissociation constants, which are similar to those of well-known anodizing electrolytes such as sulfuric, oxalic, and phosphoric acids. This paper describes how anodic porous alumina can be formed on the aluminum substrate via squaric acid anodizing under typical anodizing conditions. The growth behavior and nanostructure of the formed porous alumina are examined in terms of electrochemical measurements and SEM observations.

\section{Experimental}

\subsection{Squaric acid anodizing of aluminum}

Highly pure aluminum foils $(99.99 \mathrm{wt} \%, 110 \mu \mathrm{m}$ thick, Showa Aluminum Co., Japan, impurities: $\mathrm{Fe} 10 \mathrm{ppm}$, Si 9 ppm, and $\mathrm{Cu} 57 \mathrm{ppm}$ ) were used as the specimens. The specimens were cut into $20 \mathrm{~mm}$ x $20 \mathrm{~mm}$ pieces with a handle and then ultrasonically degreased in an ethanol solution for $10 \mathrm{~min}$ as a pretreatment. In this investigation, no electropolishing was carried out to avoid the delay of porous alumina formation, as reported previously [30]. Squaric acid anodizing was carried out under typical anodizing conditions using high concentrated solution at room temperature. The degreased specimens were immersed in a $0.1 \mathrm{M}$ squaric acid solution $\left(11.41 \mathrm{gL}^{-1}, \mathrm{pH}\right.$ of the solution is 1.16 at $293 \mathrm{~K}$ ) and then anodized for up to $360 \mathrm{~min}$ at a constant current density of 10-200 $\mathrm{Am}^{-2}$ or applied potential of 100-150 V (Direct current power supply PWR400H, Kikusui, Japan). A platinum plate (99.98 wt\%, $110 \mu \mathrm{m}$ thick, Nilaco, Japan) was used as the counter electrode. During the anodizing, the temperature of the squaric acid solution was held at $293 \mathrm{~K}$ by a water bath (UCT-1000, AS ONE, Japan), and the solution was stirred with a magnetic stirrer. The current density during the 
constant-voltage anodizing was measured using a digital multi-meter (DMM4040, Tektronix). After anodizing, the specimens were washed with distilled water and then dried in a desiccator.

\subsection{Characterization of the anodized specimens}

Several anodized specimens were immersed in a $0.20 \mathrm{M} \mathrm{CrO} / 0.54 \mathrm{M} \mathrm{H}_{3} \mathrm{PO}_{4}$ solution $(\mathrm{T}=353 \mathrm{~K})$ for up to $10 \mathrm{~min}$ to selectively dissolve the anodic oxide film. The surface morphology of the anodized and post-treatment specimens was examined by field-emission scanning electron microscopy (FE-SEM, JSM-6500F and JIB-4600F/HKD, JEOL). Distributions of aluminum, oxygen, and carbon on the anodized specimens were also examined by energy dispersive X-ray spectroscopy (EDS, JIB-4600F/HKD, JEOL). The phase compositions of the anodized specimen were determined using X-ray diffraction (XRD, XpertPro, Phillips) analysis. For vertical cross-sectional observations, two treated specimens were prepared: a) one group of specimens was embedded in an epoxy resin, polished mechanically, and then immersed in a $0.25 \mathrm{M} \mathrm{K}_{3}\left[\mathrm{Fe}(\mathrm{CN})_{6}\right] / 4.17 \mathrm{M} \mathrm{NaOH}$ solution at room temperature for $15-90 \mathrm{~s}$ to clearly observe the anodic oxide. b) the other group of specimens was mechanically cut in liquid nitrogen. For each SEM observation, the anodized specimens were sputter-coated with platinum using a sputter coater (MSP-1S, Vacuum Device, Japan).

\section{Results and discussion}

\subsection{Constant-Current and -Voltage Anodizing in Squaric Acid Solution}

Fig. 2 shows the changes in applied potential, $\Delta V$, with anodizing time, $t_{a}$, in a $0.1 \mathrm{M}$ squaric acid solution at $293 \mathrm{~K}$ and constant current density of $\mathrm{j}=10,25,50,100$, and $200 \mathrm{Am}^{-2}$ for $30 \mathrm{~min}$. For $\mathrm{j}=10 \mathrm{Am}^{-2}$, the applied potential initially increased linearly with anodizing time and then reached a maximum value of $\Delta \mathrm{V}=125 \mathrm{~V}$ at $\mathrm{t}_{\mathrm{a}}=12 \mathrm{~min}$. After this linear increase, the applied potential slightly decreased for a few minutes and then remained at a steady value of approximately $120 \mathrm{~V}$. This current density-anodizing time transient, namely, a) increasing, b) slightly decreasing, and c) steady, is similar to that observed for anodic porous alumina growth in typical acidic solutions [45], and the changes correspond to a) barrier oxide growth on the aluminum substrate, b) porous layer formation by selective dissolution of the oxide, and c) steady-state growth of the anodic porous alumina, respectively. At 25 and $50 \mathrm{Am}^{-2}$, the applied potentials show nearly the same steady value of $120 \mathrm{~V}$ after the initial period, although the slope of the $\Delta \mathrm{V}-\mathrm{t}_{\mathrm{a}}$ lines for barrier layer formation is much steeper than that for $10 \mathrm{Am}^{-2}$ due to the increasing growth rate of the barrier oxide. During barrier oxide formation, the oxide film thickness, $\delta$, is proportional to the electrochemical potential (applied potential or cell voltage), $\mathrm{E}_{\mathrm{a}}$, and can be calculated using the following equation

$$
\delta=\mathrm{K} \mathrm{E}_{\mathrm{a}}
$$

where $\mathrm{K}$ is a proportionality constant, generally $1.3-1.6 \mathrm{nmV}^{-1}[46,47]$. After this barrier oxide growth, a porous layer was formed by selective oxide dissolution at the 
surface of barrier oxide. Therefore, the applied potential slightly decreased due to the decreasing of the barrier oxide thickness at the pore bottom, as described in Fig. 2. Finally, the steady-state growth of the anodic porous alumina proceeded, and the applied potential was almost unchanged at approximately $120 \mathrm{~V}$. Namely, thickness of the barrier oxide at the pore bottom was also unchanged.

At $100 \mathrm{Am}^{-2}$, the applied potential for the porous layer formation increased gradually with the anodizing time, indicating that $\Delta \mathrm{V}=150 \mathrm{~V}$ at $\mathrm{t}_{\mathrm{a}}=30 \mathrm{~min}$. At $200 \mathrm{Am}^{-2}$, the applied potential increased rapidly to over $200 \mathrm{~V}$ within $12 \mathrm{~min}$, and intense gas evolution was observed from the aluminum anode due to "burning" by the electric current [28]. From these electrochemical measurements, constant-voltage anodizing over the range of 100-150 V (yellowish region in Fig. 2) was performed to form anodic oxides.

The changes in current density with anodizing time at several constant applied potential in a $0.1 \mathrm{M}$ squaric acid solution over $360 \mathrm{~min}$ are shown in Fig. 3a). In addition, to clearly understand the changes observed during in the initial anodizing period, the current-time transients of the same anodizing procedure over a period of 50 min are also shown in Fig. 3b). At $150 \mathrm{~V}$, the current density increased rapidly to over $2000 \mathrm{Am}^{-2}$ within a few seconds, and oxygen gas evolution was observed from the specimen due to burning. At other applied potentials, the current density remained constant at a small value of approximately 1-3 $\mathrm{Am}^{-2}$ after the initial 50-min period. In the initial period, the current density at $120 \mathrm{~V}$ showed a large peak of $200 \mathrm{Am}^{-2}$, which decreased with applied potential, as shown in Fig. 3b). This peak current is typically observed during the constant-voltage anodizing of aluminum for porous alumina fabrication. According to the growth model of anodic porous alumina during constant-voltage anodizing, the current-time transient shows two overlapping processes of oxide growth: barrier and porous layer formation [48]. The current density at the beginning of anodizing corresponded to the period of barrier layer formation (drastic current increasing and decreasing within $2 \mathrm{~min}$ ), and the period after the barrier layer formation corresponded to porous layer formation. As indicated by the results of constant-current and -voltage anodizing shown in Figs. 2 and 3, these electrochemical behaviors strongly suggest that squaric acid has the potential behave as a suitable new electrolyte for the fabrication of anodic porous alumina. The anodized specimens were carefully examined by SEM, as described in the next section.

3.2 Micro- and Nano-Scale Features of the Anodic Oxide Formed by Squaric Acid Anodizing

The surfaces of the anodized specimens obtained by squaric acid anodizing at 100-150 V are shown in Fig. 4a); the changes in current density observed for these specimens are shown in Fig. 3. The specimens anodized at 100 and $110 \mathrm{~V}$ showed an aluminum layer with a uniform dark-yellowish color, and the color of the anodic oxide gradually became darker with anodizing time due to the increase in the thickness of the 
anodic oxide obtained by anodizing in organic acids such as oxalic acid. At $120 \mathrm{~V}$, an anodic oxide with a darker yellowish color was formed on the aluminum layer, and light-gray oxide regions were also observed at the center of the anodized specimens (red arrow). An extremely thin anodic oxide layer was formed at $150 \mathrm{~V}$ because of the burning phenomenon that occurred with oxygen gas evolution. The light-gray oxides observed at $120 \mathrm{~V}$ will be discussed in greater detail in section 3.3, and the typical yellowish oxides formed at 100-120 V are discussed in the following section.

Fig. 4b) shows an SEM image of the surface appearance of specimen anodized in squaric acid at $100 \mathrm{~V}$ for $120 \mathrm{~min}$. The stripe pattern observed from the upper right to the lower left of the image corresponds to the marks formed by the rolling of the aluminum foil. Many nanopores are observed along the rolling marks on the anodic oxide, and the diameters of the nanopores were measured to be approximately 20-50 nm. The pore distribution did not possess a close-packed hexagonal pattern, as obtained in a previously reported highly ordered porous alumina film. When anodic porous alumina is formed on an aluminum substrate via anodizing, its nanopores are generally formed in a disorderly fashion on the top of the anodic oxide during the initial stage of anodizing. The nanopores then gradually become ordered at the interface between the anodic oxide and aluminum substrate under the appropriate conditions of constant-voltage anodizing. Therefore, observations of the oxide-aluminum interface are very important in understanding the growth behavior of the porous alumina layer. Fig. 4c) shows an SEM image of the interface after anodizing at $100 \mathrm{~V}$ for $120 \mathrm{~min}$. The specimen was immersed in $\mathrm{CrO}_{3} / \mathrm{H}_{3} \mathrm{PO}_{4}$ solution to selectively dissolve the anodic oxide. Disordered dimples measuring approximately 210-380 $\mathrm{nm}$ in diameter were distributed on the aluminum substrate; however, the nanodimple array was also disordered under these conditions.

An SEM image of the vertical cross-section of the specimen anodized at $120 \mathrm{~V}$ for $360 \mathrm{~min}$ is shown in Fig. 5a). For cross-sectional observation, the anodized specimen was mechanically cut in liquid nitrogen. An anodic oxide film with a thickness greater than $10 \mu \mathrm{m}$ was formed on the aluminum substrate, and numerous fine nanopores were observed in the anodic oxide. The nanopores formed in the anodic oxide developed greater curvature as they grew, and the growth directions of the nanopores were not uniformly straight. These growth behaviors of the porous layer via squaric acid anodizing are summarized in Fig. 8. Most notably, it is clear from Fig. 5a) that anodic porous alumina can be fabricated by squaric acid anodizing.

Fig. 5b) shows a high-magnification SEM image of the anodic oxide formed via squaric acid anodizing at $120 \mathrm{~V}$ for $360 \mathrm{~min}$. Nanometer-scale platinum particles were observed on the anodic oxide, as were nanopores due to electro-conductive platinum deposition using a sputter coater. The diameter of the nanopores was measured to be approximately $80 \mathrm{~nm}$. Barrier oxides were clearly observed at the bottom of the anodic porous alumina, and the mean thickness of the barrier layer was determined to be approximately $140 \mathrm{~nm}$. The proportionally constant $(\mathrm{K})$ for the barrier oxide can be 
calculated using the following equation

$$
\mathrm{K}=\delta / \mathrm{E}_{\mathrm{a}}
$$

By substituting $140 \mathrm{~nm}$ for $\delta$ and $120 \mathrm{~V}$ for $\mathrm{E}_{\mathrm{a}}, \mathrm{K}$ is estimated to be $1.17 \mathrm{nmV}^{-1}$. This value is smaller than the values obtained for barrier oxides formed by anodizing in neutral solutions, as described above (Fig. 2). During anodizing in acidic electrolytes, aluminum ions are generated at the interface between the aluminum substrate and oxide via the following electrochemical reaction [21]:

$$
\mathrm{Al}=\mathrm{Al}^{3+}+3 \mathrm{e}^{-}
$$

Oxygen ions are also generated at the interface between the oxide and solution via the following electrochemical reaction:

$$
\mathrm{H}_{2} \mathrm{O}=\mathrm{O}^{2-}+2 \mathrm{H}^{+}
$$

At the same time, aluminum ions dissolve into the solution at the oxide-solution interface of the pore bottom.

$$
\mathrm{Al}^{3+} \text { (oxide) }=\mathrm{Al}^{3+}(\mathrm{aq})
$$

Therefore, the thickness of the barrier oxide formed in acidic solutions is smaller than that in neutral solutions due to the active chemical dissolution of the anodic oxide at the pore bottom. In fact, small proportionally constant values during anodic porous alumina fabrication have already been reported for other acidic electrolytes [23].

Fig. 6 shows X-ray diffraction patterns obtained from the a) as-received aluminum foil and b) anodized aluminum specimen in squaric acid solution. The XRD pattern shows three peaks corresponding to the (200), (220), and (311) planes of the aluminum substrate. Comparing Fig. 6a) with b), a typical amorphous pattern of the anodic oxide was observed at angles between 20 and 40 degrees after anodizing in squaric acid solution. The anodic oxide consisted of amorphous $\mathrm{Al}_{2} \mathrm{O}_{3}$ containing 5-6 at $\%$ carbon from the electrolyte by spot EDX measurements at different positions.

Fig. 7 shows SEM images of the aluminum substrate of the specimen anodized in squaric acid solution at $110 \mathrm{~V}$ for a) 30, b) 120, and c) $360 \mathrm{~min}$, after selective oxide dissolution in $\mathrm{CrO}_{3} / \mathrm{H}_{3} \mathrm{PO}_{4}$ solution. As in the specimen shown in Fig. 4b), fabricated at $100 \mathrm{~V}$, a disordered dimple array was also formed on the aluminum substrate at an applied potential of $110 \mathrm{~V}$, although the mean diameter of the dimples was larger than that of the dimples formed at $100 \mathrm{~V}$. The dimple diameter increased with anodizing time (Figs. 6a through 6c), and dimples measuring 300-420 $\mathrm{nm}$ in diameter were also disordered after anodizing for a long period of $360 \mathrm{~min}$. The dimple diameter also increased with time at other applied potentials, demonstrating same tendency. Long anodizing times, generally causes the self-ordering of anodic porous alumina under appropriate anodizing conditions, and an ideal hexagonal nanodimple array is formed on the aluminum substrate. However, self-ordered porous alumina could not be obtained by anodizing in squaric acid at room temperature until the anodizing time reached 360 min. To understand the uneven growth of the anodic porous alumina, the bottom of the porous oxide layer was studied by observing the vertical cross-section of a specimen.

An SEM image of the vertical cross-section of a specimen anodized at $120 \mathrm{~V}$ for 360 
min is shown in Fig. 8a). The specimen was embedded in an epoxy resin and then polished mechanically. Therefore, the nanopores in the anodic oxide could not be clearly observed. The shape of the oxide-metal interface corresponds to that of the nanodimple array formed on the aluminum substrate shown in Fig. 7c), and the disordered growth of the porous oxide is also clearly illustrated in Fig. 8a). In particular, it is noted that the bottom of the anodic porous alumina film is not parallel to the growth plane, which occurs because the growth rate of each cell is slightly different during squaric acid anodizing.

A high-magnification SEM image of a cross-sectional anodized specimen obtained by cutting in liquid nitrogen is shown in Fig. 8b). It is observed that two nanopores in the anodic oxide (indicated by yellow arrows) grew more rapidly than the sandwiched nanopore at the center. In the case of this uneven growth, the growth of the sandwiched nanopore will rapidly cease due to the lack of a direction for growth (dead pore) [49]. Therefore, the diameter of the nanopores on both sides increases due to dead pores, as shown in Fig. 7. Further investigation of porous layer formation during squaric acid anodizing will be required to understand this uneven growth rate of the anodic porous alumina film.

Fig. 9 shows changes in film thickness of the anodic porous alumina, $\delta$, with anodizing time, $t_{a}$, during constant-voltage anodizing in squaric acid solution. The anodic porous alumina grew rapidly in the initial stage of anodizing $\left(t_{a}=50 \mathrm{~min}\right)$. After this increase, the growth rate of the film gradually decreased. In addition, the anodic porous alumina formed at $110 \mathrm{~V}$ was thicker than that at $100 \mathrm{~V}$. These film growth behaviors are in fair agreement with the current density changing at several applied potentials, as shown in Fig. 3 b.

Porous anodic oxide film was successfully fabricated by anodizing in squaric acid solution, as described in Figs. 4-9. Anodizing in typical carboxylic electrolytes, including oxalic, malonic, tartaric, and citric acids, causes the formation of uniform porous alumina layer on aluminum substrate. Conversely, it was observed that the porous alumina formed in squaric acid is slightly non-uniform film (Fig. 8). Its morphology and uneven pore growth are similar to that of the porous alumina formed by glycolic acid anodizing, as reported previously [23]. The film formation voltage in sauaric acid (100-150 V) was smaller than that in tartaric (235-240 V), citric (270-370 $\mathrm{V})$, and malic (220-450 V) acids, and was similar values as oxalic (40-160 V) and malonic acids $(100-120 \mathrm{~V})[23,30,34]$. This is may be due to the low dissociation constants of squaric acid, as described in introduction.

In this study, we could not obtained a self-ordered porous alumina film with an ideal hexagonal structure. The selected anodizing conditions, squaric acid concentration of $0.1 \mathrm{M}$, temperature of $293 \mathrm{~K}$, and applied potential of $100-120 \mathrm{~V}$, may not be suitable for the self-ordering of anodic porous alumina. Anodizing in squaric acid under other electrochemical conditions will be further investigated for the fabrication of highly-ordered anodic porous alumina, and the results will be reported in the near 
future.

3.3 Deposition of Numerous Thin Films on Anodic Porous Alumina by Anodizing at High Voltage

The surface of the anodic porous alumina formed by anodizing in squaric acid is shown in Fig. 4a), which indicates that light-gray oxides were locally formed at $120 \mathrm{~V}$. To further study this specimen anodized at high voltage, the surface of the anodic porous alumina film was continuously investigated by SEM observation. Fig. 10 shows SEM images of the a) dark-yellowish and b) light-gray oxide regions formed at $120 \mathrm{~V}$ and shown in Fig. 4a). A typical uniform anodic oxide film with numerous nanopores was formed on the yellowish oxide region, and a strip pattern formed by the rolling of the aluminum foil was also observed (Fig. 10a). In contrast, numerous tetragonal thin films measuring a few $\mu \mathrm{m}$ in width were observed on the light-gray oxide region (Fig. 10b). The formation of these thin films could not be observed on the specimen anodized at low voltages. As indicated by the high-magnification SEM image shown in the insert (Fig. 10b), there were no nanopores on the thin film, and the film surface was flat. Thus, it is clear that the thin films were not anodic porous alumina.

An SEM image of thin-film-deposited anodic porous alumina was obtained from a declined angle, as shown in Fig. 11a). The specimen was mechanically cut before SEM observation, and two crevasses formed by the mechanical cutting of the specimen are shown at the center of the figure. The thicknesses of the thin films on the anodic oxide were determined to be approximately $50-300 \mathrm{~nm}$, and the films were not only formed horizontally on the anodic oxide but also vertically. In addition, it was also observed that a film was formed on top of another film. High-magnification SEM observations indicated that no nanopores were formed on the thin films, as also shown in Fig. 10b). From the observations made, it is concluded that these thin films were deposited on the anodic porous alumina form the aqueous solution during high-voltage anodizing but were not separated from the anodic porous alumina. Fig. 11b) shows the oxygen, carbon, and aluminum element distributions obtained by EDS analysis of the thin film shown in Fig. 11a), where the scales to the right of the images indicate the relative intensities of oxygen, carbon, and aluminum. Focusing on the thin film along the crevasse (at the center of Fig. 11b), the anodic porous alumina showed no effect on the EDS measurements of the thin film. By comparing the oxygen, carbon, and aluminum distributions on the thin film and anodic porous alumina, it can be ascertained that carbon was highly distributed over the thin film, and the film also contained oxygen and aluminum, although their intensities were lower than those observed on anodic alumina. These distributions suggest that the thin film formed on the anodic porous alumina consisted of an aluminum complex of squaric acid. During squaric acid anodizing, aluminum ions dissolve into the solution at the pore bottom, as described by eq. (7). Therefore, there are only squarate anions, protons, and aluminum cations in the anodizing solution. Because the concentration of aluminum ions in the solution 
increases with anodizing time, a squaric acid complex will be formed and deposited on the anodic porous alumina via the following chemical reaction:

$$
2 \mathrm{Al}^{3+}+3 \mathrm{SQ}^{2-}=\mathrm{Al}_{2} \mathrm{SQ}_{3}
$$

The deposition of this complex on the anodic porous alumina may inhibit further anodic oxide growth during anodizing. Therefore, studying this phenomenon during squaric acid anodizing is important to obtaining thick and uniform porous anodic alumina films.

In summary, we fabricated the first anodic porous alumina film formed using squaric acid as the electrolyte. Unlike conventional carboxylic electrolytes used for anodic porous alumina fabrication shown in Fig. 1 (oxalic, malonic, tartaric, malic, citric, and glycolic acids), this organic electrolyte possesses a cyclic organic structure and a strong acid dissociation constant. A characteristic anodic porous alumina film with micrometer-scale thickness and submicron-scale cell size could be produced by squaric acid anodizing at 100-120 V. In general, the self-ordering of anodic porous alumina can be generally achieved at the maximum voltage required to induce high-current-density anodizing without burning. Therefore, high-current-density anodizing in squaric acid at low temperature should be further investigated to avoid oxide burning. Further investigation of squaric acid anodizing under other electrochemical conditions will be required for anodic porous alumina applications.

\section{Conclusions}

This paper described the growth behavior of the first anodic porous alumina film formed by squaric acid anodizing under constant applied potentials. The following conclusions may be drawn from the results of the electrochemical measurements and SEM observations performed in this study.

1) Anodic porous alumina can be fabricated via anodizing in a $0.1 \mathrm{M}$ squaric acid solution at $293 \mathrm{~K}$ and below a applied potential of $120 \mathrm{~V}$; however, burned oxide is formed by anodizing at higher electric fields.

2) The fabricated porous alumina exhibits micrometer-scale thickness, submicron-scale cell size, and sub-100-nm scale pores. The cell size of the porous alumina increases with anodizing time due to uneven porous layer growth.

3) The anodic porous alumina obtained by squaric acid anodizing consists of amorphous $\mathrm{Al}_{2} \mathrm{O}_{3}$ containing 5-6 at $\%$ carbon from the electrolyte.

\section{Acknowledgements}

The authors would like to thank Mr. Nobuyuki Miyazaki and Mr. Takashi Endo (Hokkaido University) for their assistance in SEM observations and EDS analysis. This research work was financially supported by the Japan Society for the Promotion of Science (JSPS) "KAKENHI” and Japan Aluminum Association.

References

1) K. Yasui, T. Morikawa, K. Nishio, H. Masuda, Patterned magnetic recording media 
using anodic porous alumina with single domain hole configurations of $63 \mathrm{~nm}$ hole interval, Japanese Journal of Applied Physics 44 (2005) L469.

2) M.T. Rahman, X. Liu, A. Morisako, TbFeCo perpendicular magnetic recording media deposited on nanohole arrays of porous alumina layer, Journal of Applied Physics 99 (2006) 08G9041.

3) S. Zhang, L. Wang, C. Xu, A. Li, L. Chen, D. Yang, Fabrication of Ni-NiO-Cu Metal-Insulator-Metal Tunnel Diodes via Anodic Aluminum Oxide Templates, ECS Solid State Letters 2 (2013) Q1.

4) G. Macias, L. P. Hernandes-Eguia, J. Ferre-Borrull, J. Pallares, L. F. Marsal, Gold-Coated Ordered Nanoporous Anodic Alumina Bilayers for Future Label-Free Interferometric Biosensors, ACS Applied Materials \& Interfaces 5 (2013) 8093.

5) H. Masuda, M. Yamada, F. Matsumoto, S. Yokoyama, S. Mashiko, M. Nakao, K. Nishio, Lasing from two-dimensional photonic crystals using anodic porous alumina, Advanced Materials 18 (2006) 213.

6) J. Choi, Y. Luo, R.B. Wehrspohn, R. Hillebrand, J. Schilling, U. Göele, Perfect two-dimensional porous alumina photonic crystals with duplex oxide layers, Journal of Applied Physics 94 (2003) 4757.

7) Q. Lin, B. Hua, S. F. Leung, X. Duan, Z. Fan, Efficient Light Absorption with Integrated Nanopillar/Nanowell Arrays for Three-Dimensional Thin-Film Photovoltaic Applications, ACS Nano 3 (2013) 2725.

8) T. Kikuchi, Y. Wachi, T. Takahashi, M. Sakairi, R.O. Suzuki, Fabrication of a meniscus microlens array made of anodic alumina by laser irradiation and electrochemical techniques, Electrochimica Acta 94 (2013) 269.

9) H. Jha, T. Kikuchi, M. Sakairi, H. Takahashi, Microfabrication of an Anodic Oxide Film by Anodizing Laser-textured Aluminum, Journal of Micromechanics and Microengineering 17 (2007) 1949.

10) T. Kondo, H. Masuda, K. Nishio, SERS in Ordered Array of Geometrically Controlled Nanodots Obtained Using Anodic Porous Alumina, Journal of Physical Chemistry C 117 (2013) 2531.

11) T. Kondo, H. Miyazaki, K. Nishio, H. Masuda, Surface-enhanced Raman scattering on multilayered nanodot arrays obtained using anodic porous alumina mask, Journal of Photochemistry and Photobiology A: Chemistry 221 (2011) 199.

12) S. Shukla, K-T. Kim, A. Baev, Y. K. Yoon, N. M. Litchinitser, P. N. Prasad, Fabrication and Characterization of Gold-Polymer Nanocomposite Plasmonic Nanoarrays in a Porous Alumina Template, ACS Nano 4 (2010) 2249.

13) T. Kikuchi, Y. Wachi, M. Sakairi, R. O. Suzuki, Aluminum Bulk Micromachining through an Anodic Oxide Mask by Electrochemical Etching in an Acetic Acid / Perchloric Acid Solution, Microelectronic Engineering 111 (2013) 14.

14) T. Kikuchi, M. Sakairi, H. Takahashi, Growth of Porous Type Anodic Oxide Films at Micro-Areas on Aluminum Exposed by Laser Irradiation, Electrochim. Acta 54 (2009) 7018. 
15) T. Kikuchi, Y. Akiyama, M. Ueda, M. Sakairi, H. Takahashi, Fabrication of a three-dimensional micro-manipulator by laser irradiation and electrochemical techniques and the effect of electrolytes on its performance, Electrochim. Acta 52 (2007) 4480.

16) J. Wang, M. Singh, M. Tian, N. Kumar, B. Liu, C. Shi, J. K. Jain, N. Samarth, T. E. Mallouk, M. H. W. Chan, Interplay between superconductivity and ferromagnetism in crystalline nanowires, Nature Physics, 6 (2010) 389.

17) F. Keller, M. S. Hunter, D. L. Robinson, Structural Features of Oxide Coatings on Aluminum, Journal of the Electrochemical Society 100 (1953) 411.

18) G. E. Thompson, R. C. Furneaux, G. C. Wood, J. A. Richardson, J. S. Gode, Nucleation and growth of porous anodic films on aluminium, Nature 272 (1978) 433.

19) G. E. Thompson, G. C. Wood, Porous anodic film formation on aluminum, Nature 290 (1981) 230.

20) R. C. Furneaux, W. C. Rigby, A. P. Davidson, The formation of controlled-porosity membranes from anodically oxidized aluminum, Nature 337 (1989) 147.

21) J. E. Houser, K. R. Hebert, The role of viscous flow of oxide in the growth of self-ordered porous anodic alumina films, Nature Materials 8 (2009) 415.

22) K. R. Hebert, S. P. Albu, I. Paramasivam, P. Schmuki, Morphological instability leading to formation of porous anodic oxide films, Nature Materials 11 (2012) 162.

23) S.Z. Chu, K. Wada, S. Inoue, M. Isogai, Y. Katsuta, A. Yasumori, Large-scale fabrication of ordered nanoporous alumina films with arbitrary pore intervals by critical-potential anodization, Journal of the Electrochemical Society 153 (2006) B384.

24) H. Masuda, K. Fukuda, Ordered metal nanohole arrays made by a two-step replication of honeycomb structures of anodic alumina, Science 268 (1995) 1466.

25) W. Lee, R. Ji, U. Gösele, K. Nielsch, Fast fabrication of long-range ordered porous alumina membranes by hard anodization, Nature Materials 5 (2006) 741.

26) W. Lee, K. Schwirn, M. Steinhart, E. Pippel, R. Scholz, U. Gösele, Structural engineering of nanoporous anodic aluminum oxide by pulse anodization of aluminum, Nature Nanotechnology 3 (2008) 234.

27) A-P. Li, F. Müller, A. Birner, K. Nielsh, U. Gösele, Polycrystalline nanopore arrays with hexagonal ordering on aluminum, Journal of Vacuum Science \& Technology A 17 (1999) 1428.

28) S. Ono, M. Saito, M. Ishiguro, H. Asoh, Controllong factor of self-ordering of anodic porous alumina, Journal of the Electrochemical Society 151 (2004) B473.

29) M. Michalska-Domanska, M. Norek, W. J. Stepniowski, B. Budner, Fabrication of high quality anodic aluminum oxide (AAO) on low purity aluminum-A comparative study with the AAO produced on high purity aluminum, Electrochim Acta 105 (2013) 424.

30) S. Ono, M. Saito, H. Asoh, Self-ordering of anodic porous alumina formed in organic acid electrolytes, Electrochimica Acta, 51 (2005) 827. 
31) W. Lee, K. Nielsch, U. Gösele, Self-ordering behavior of nanoporous anodic aluminum oxide (AAO) in malonic acid anodization, Nanotechnology 18 (2007) 475713.

32) S. J. Garcia-Vergara, P. Skeldon, G. E. Thompson, H. Habazaki, A tracer investigation of chromic acid anodizing of aluminum, Surface and Interface Analysis 39 (2007) 860.

33) V. P. Parkhutik, J. M. Albella, Y. E. Makushok, I. Montero, J. M. Martinez-Duart, V. I. Shershulskii, Study of aluminum anodization in sulphuric and chromic acid solutions-I kinetics of growth and composition of oxides, Electrochimica Acta 35 (1990) 955.

34) T. Kikuchi, T. Yamamoto, and R. O. Suzuki, Growth Behavior of Anodic Porous Alumina Formed in Malic Acid Solution, Applied Surface Science, 284 (2013) 907.

35) S. Ono, S. Chiaki, T. Sato, Micro-Structure of Anodic Oxide Film on Aluminum Formed in Chromic Acid Solution, Journal of the Surface Finishing Society of Japan, 26 (1975) 456.

36) A. Mozalev, I. Mozalev, M. Sakairi, H. Takahashi, Anodic film growth on Al layers and Ta-Al metal bilayer in citric acid electrolytes, Electrochimica Acta, 50 (2005) 5065 .

37) M. A. Kashi, A. Ramazani, M. Rahmandoust, M. Noormohammadi, The effect of $\mathrm{pH}$ and composition of sulfuric-oxalic acid mixture on the self-ordering configuration of high porosity alumina nanohole arrays, Journal of Physics D: Applied Physics 40 (2007) 4625.

38) J. Martin, C. V. Manzano, O. Caballero-Calero, M. Martin-Gonzalez, High-Aspect-Ration and Highly Ordered 15-nm Porous Alumina Templates, ACS Applied Materials \& Interfaces 5 (2013) 72.

39) O. Nishinaga, T. Kikuchi, S. Natsui, R. O. Suzuki, Rapid fabrication of self-ordered porous alumina with 10-/sub-10-nm-scale nanostructures by selenic acid anodizing, Scientific reports 3 (2013) 2748.

40) S. Cohen, J. R. Lacher, J. D. Park, Diketocyclobutenediol, Journal of the American Chemical Society 81 (1959) 3480.

41) S. L. Georgopoulos, H. G. M. Edwards, L. F. C. de Oliveira, Raman spectroscopic analysis of the interaction between squaric acid and dimethylsulfoxide, Spectrochimica Acta Part A: Molecular and Biomolecular Spectroscopy 111 (2013) 54.

42) K. Aknin, M. Gauriot, J. Totobenazara, N. Deguine, R. Deprez-Poulain, B. Deprez, J. Charton, Squaric acid is a suitable building-block in 4C-Ugi reaction: access to original bivalent compounds, Tetrahedron Letters 53 (2012) 458.

43) J. Xie, A. B. Comeau, C. T. Seto, Squaric Acids: A New Motif for Designing Inhibitors of Protein Tyrosine Phosphatases, Organic Letters 6 (2004) 83.

44) Z. Dega-Szafran, A. Katrusiak, M. Szafran, Stable Molecular Complex of Squaric Acid with 2-(Quinuclidinium)propionate, Australian Journal of Chemistry 66 (2013) 
836.

45) G. E. Thompson, Porous anodic alumina: fabrication, characterization and applications, Thin Solid Films 297 (1997) 192.

46) H. Takahashi, M. Nagayama, Electrochemical behavior and structure of anodic oxide films formed on aluminum in a neutral borate solution, Electrochimica Acta 23 (1978) 279.

47) H. Takahashi, K. Fujimoto, M. Nagayama, Effect of $\mathrm{pH}$ on the Distribution of Anions in Anodic Oxide Films Formed on Aluminum in Phosphate Solutions, Journal of the Electrochemical Society, 135 (1988) 1349.

48) T. P. Hoar, J. Yahalom, The initiation of pores in anodic oxide films formed on aluminum in acid solutions, Journal of the Electrochemical Society 110 (1963) 614.

49) X. Zhao, G. Meng, F. Han, X. Li, B. Chen, Q. Xu, X. Zhu, Z. Chu, M. Kong, Q, Huang, Nanocontainers made of various materials with tunable shape and size, Scientific reports 3 (2013) 2238. 


\section{Captions}

Fig. 1 Summary of the anodizing electrolytes used for anodic porous alumina fabrication. The inorganic acids sulfuric, phosphoric, and chromic acids and the organic acids oxalic, malonic, tartaric, malic, citric, and glycolic acids have been reported to date. In this study, squaric acid's potential as an anodizing electrolyte was investigated.

Fig. 2 Changes in applied potential, $\Delta V$, with anodizing time, $t_{a}$, in a $0.1 \mathrm{M}$ squaric acid solution over an anodizing time of $30 \mathrm{~min}$ at $293 \mathrm{~K}$ and constant current density of $\mathrm{j}=$ $10,25,50,100$, and $200 \mathrm{~A} \mathrm{~m}^{-2}$. Ultrasonically cleaned aluminum foils were anodized in a squaric acid solution, and the solution was stirred by a magnetic stirrer during anodizing.

Fig. 3 a) Current density changes with anodizing time in squaric acid solution at different applied potentials of 100-150 V. b) Current-time transients during the initial period captured in a). At $\Delta \mathrm{V}=150 \mathrm{~V}$, the current density increased rapidly within a few seconds due to the burning of the anodic oxide.

Fig. 4 a) Surfaces of the specimens anodized in $0.1 \mathrm{M}$ squaric acid solution at 100, 110, 120 , and 150 V. b) and c) SEM images of the anodized specimen b) before and c) after selective anodic oxide removal in a $0.20 \mathrm{M} \mathrm{CrO}_{3} / 0.54 \mathrm{M} \mathrm{H}_{3} \mathrm{PO}_{4}$ solution. The specimen was anodized at $100 \mathrm{~V}$ for $120 \mathrm{~min}$.

Fig. 5 a) An SEM image of the vertical cross-section of the anodic porous alumina formed by squaric acid anodizing at $120 \mathrm{~V}$ for $360 \mathrm{~min}$. b) High-magnification SEM image of the pore-bottom of the anodic alumina, shown in a).

Fig. 6 X-ray diffraction patterns of aluminum specimens a) before and b) after anodizing in squaric acid solution.

Fig. 7 SEM images of the nanodimple array formed on the aluminum substrate by squaric acid anodizing at $110 \mathrm{~V}$ for a) 30, b) 120, and c) $360 \mathrm{~min}$.

Fig. 8 High-magnification SEM images of the vertical cross-section of a specimen anodized at $120 \mathrm{~V}$ for $360 \mathrm{~min}$. a) The specimen was embedded in an epoxy resin and then polished mechanically. b) The specimen was mechanically cut in liquid nitrogen.

Fig. 9 Changes in film thickness with anodizing time by constant voltage anodizing $(\Delta \mathrm{V}=100$ and $110 \mathrm{~V})$ in squaric acid solution.

Fig. 10 SEM images of the surface of the anodic porous alumina formed at $120 \mathrm{~V}$ for 
360 min; a) dark-yellowish and b) light-gray oxide regions shown in Fig. 4a). Each insert figure shows a high-magnification SEM image of the specimen in the area indicated by a yellow square.

Fig. 11 a) SEM images of numerous thin films formed on the anodic porous alumina. b) EDS-determined distributions of oxygen, carbon, and aluminum on the surface of the anodized specimen shown in a). 


\begin{tabular}{|c|c|c|c|c|c|}
\hline \multicolumn{3}{|c|}{ Three major electrolytes } & Self-ordered electrolytes $(6$ & & rganic acids (6) \\
\hline \multirow{2}{*}{$\begin{array}{l}\mathrm{H}_{2} \mathrm{SeO}_{4} \\
\text { Selenic }\end{array}$} & $\begin{array}{l}\mathrm{H}_{2} \mathrm{SO}_{4} \\
\text { Sulfuric }\end{array}$ & \multirow{2}{*}{$\begin{array}{l}(\mathrm{COOH})_{2} \\
\text { Oxalic }\end{array}$} & \multirow{2}{*}{$\begin{array}{c}\mathrm{HOOC}-\mathrm{CH}_{2}-\mathrm{COOH} \\
\text { Malonic } \\
\text { HOOC- }(\mathrm{CHOH})_{2}-\mathrm{COOH} \\
\text { Tartaric } \\
\end{array}$} & \multicolumn{2}{|c|}{$\begin{array}{c}\mathrm{HOOC}-\mathrm{CH}(\mathrm{OH})-\mathrm{CH}_{2}-\mathrm{COOH} \\
\text { Malic }\end{array}$} \\
\hline & $\begin{array}{c}\mathrm{H}_{3} \mathrm{PO}_{4} \\
\text { Phosphoric }\end{array}$ & & & \multicolumn{2}{|c|}{$\begin{array}{c}\mathrm{HOOC}-\mathrm{CH}_{2}-\mathrm{C}(\mathrm{OH})(\mathrm{COOH})-\mathrm{COOH} \\
\text { Citric }\end{array}$} \\
\hline \multicolumn{2}{|c|}{$\begin{array}{l}\mathrm{H}_{2} \mathrm{CrO}_{4} \\
\text { Chromic }\end{array}$} & & & \multicolumn{2}{|r|}{$\begin{array}{c}\mathrm{CH}_{2} \mathrm{OH}-\mathrm{COOH} \\
\text { Glycolic }\end{array}$} \\
\hline \multicolumn{3}{|c|}{ organic electrolytes } & $\cdot \begin{aligned} \text { Stron } \\
(p K a\end{aligned}$ & $=3.5)$ & $\begin{array}{l}\text { Anodic porous alumina } \\
\text { एथण्यधच }\end{array}$ \\
\hline
\end{tabular}

Fig. 1 


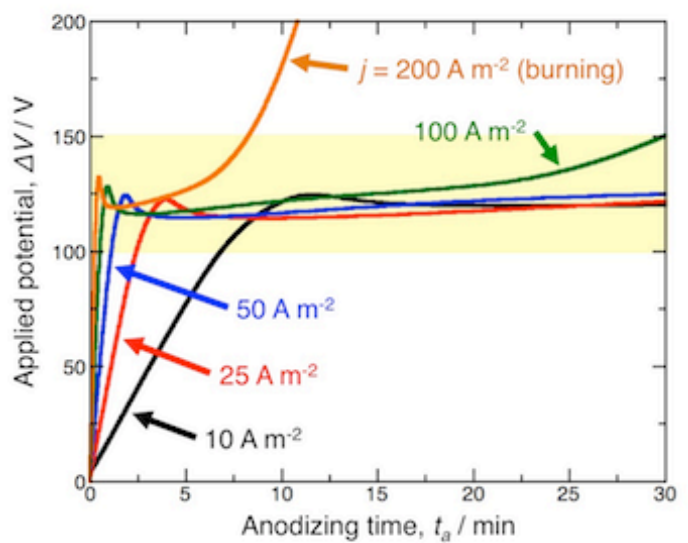

Fig. 2 


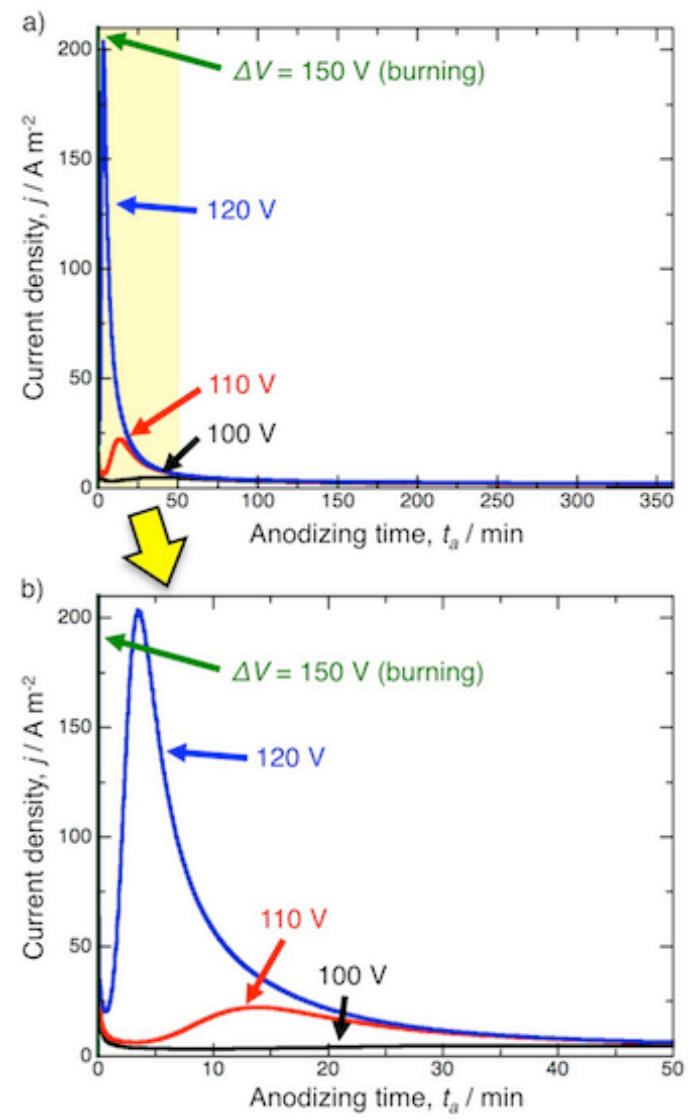

Fig. 3 
a)

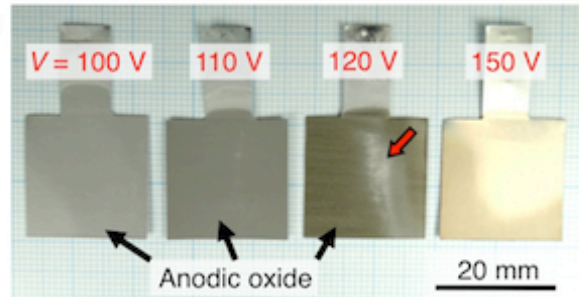

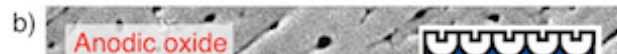

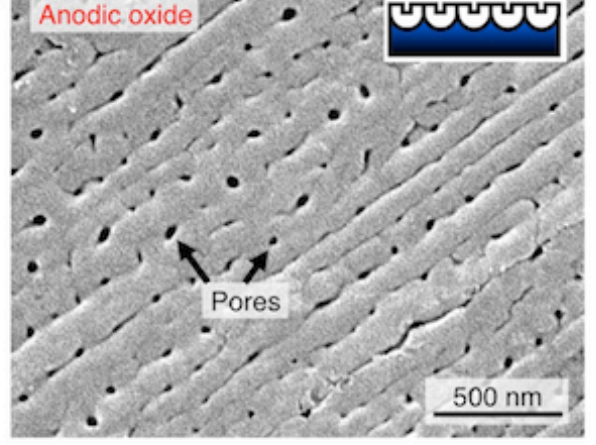

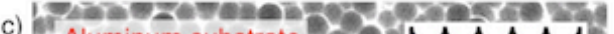

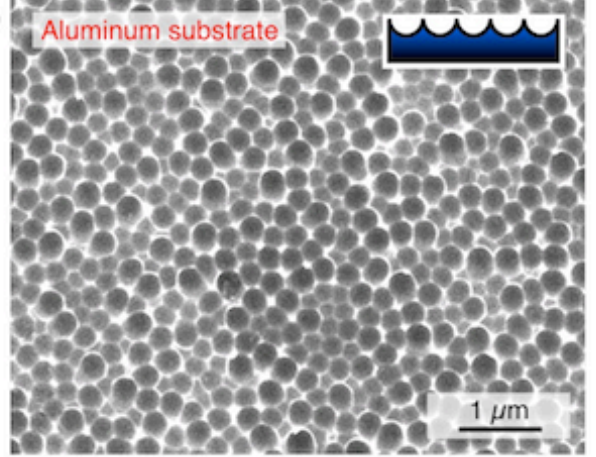

Fig. 4 


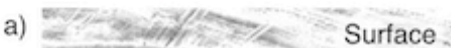

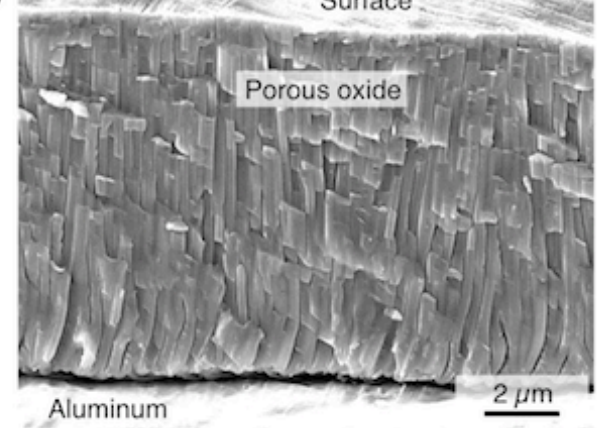

b)

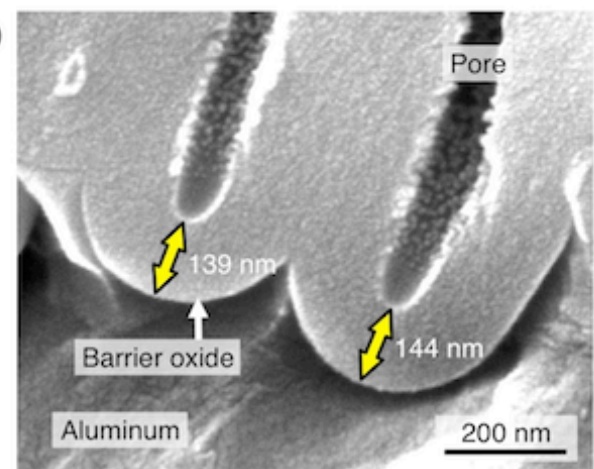

Fig. 5 


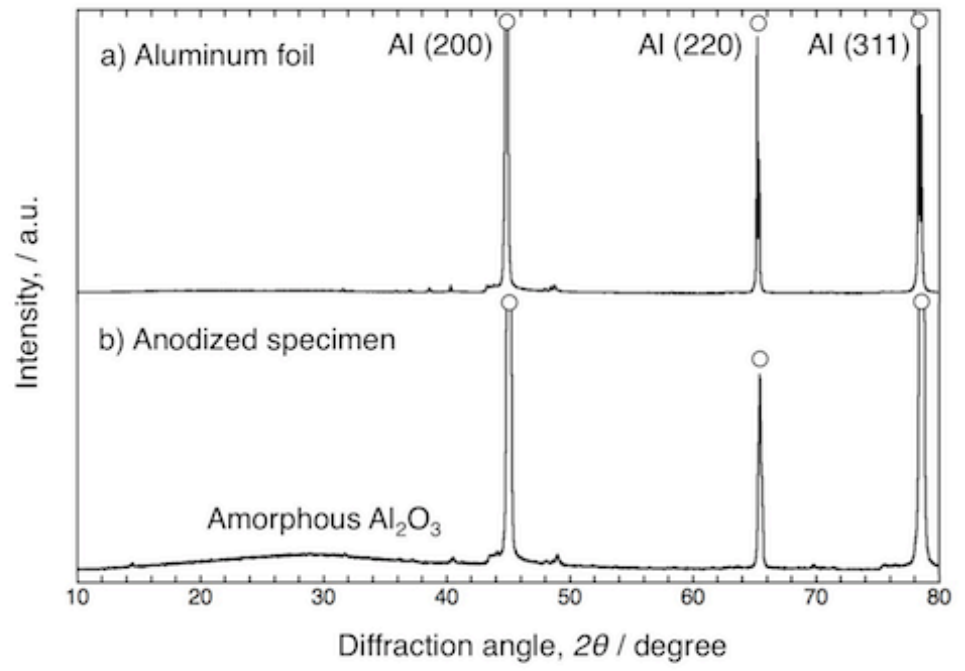

Fig. 6 


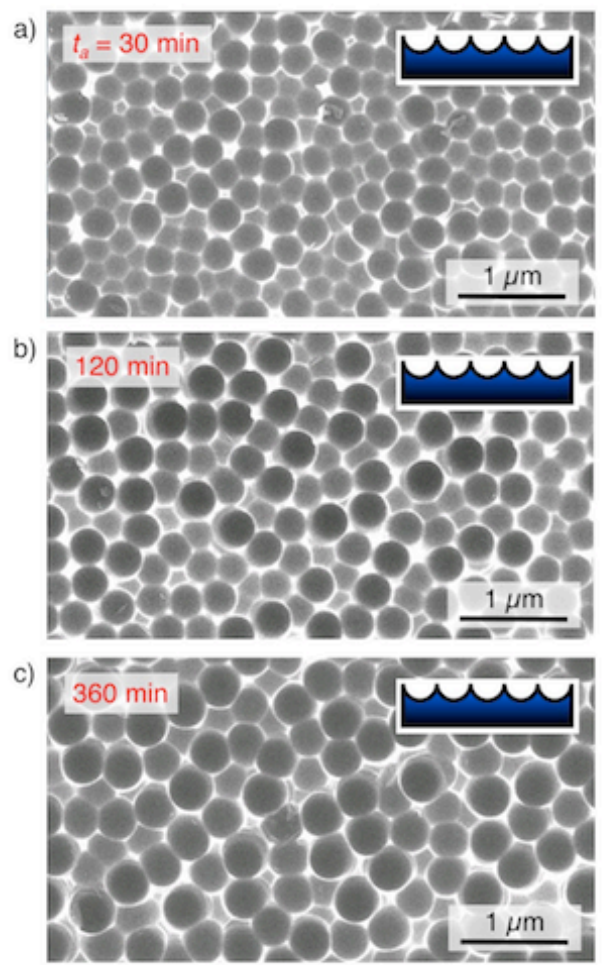

Fig. 7 
a)

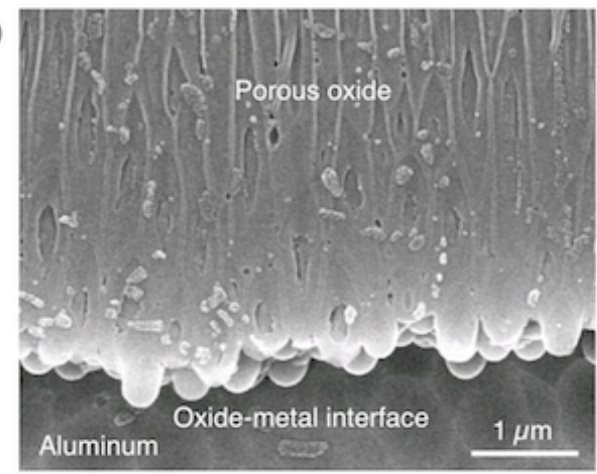

b)

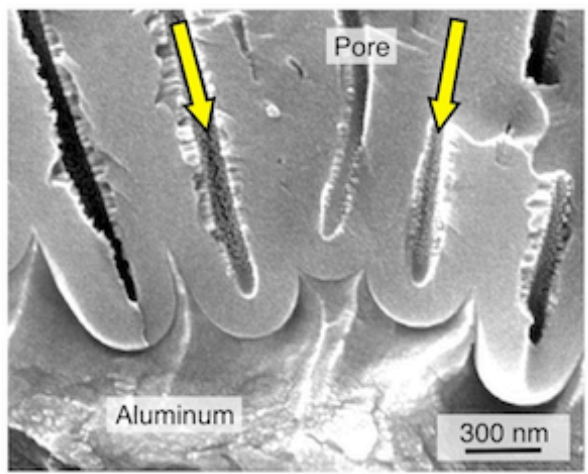

Fig. 8 


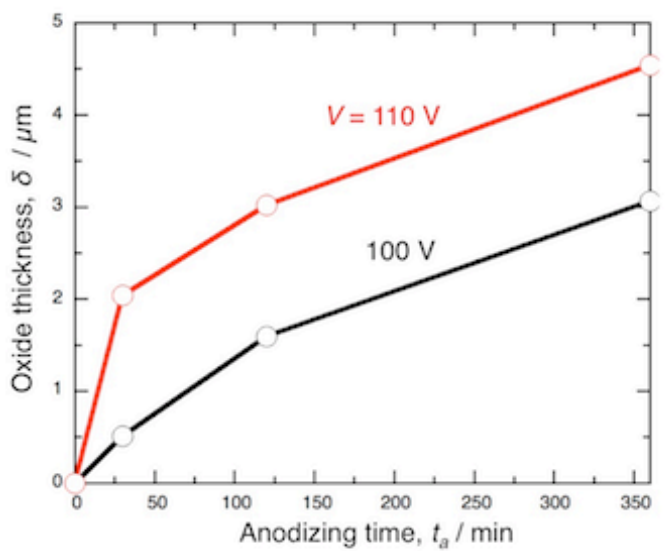

Fig. 9 
a)

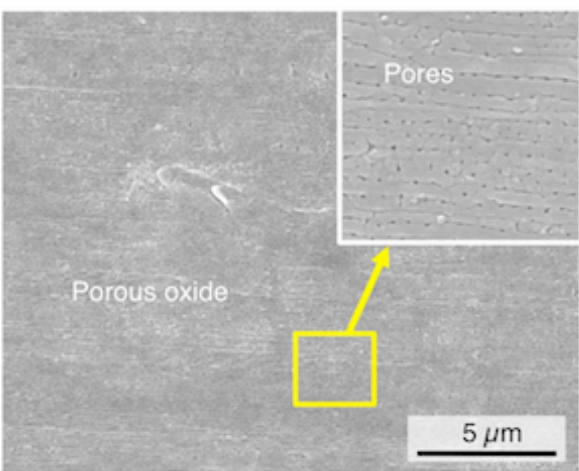

b)

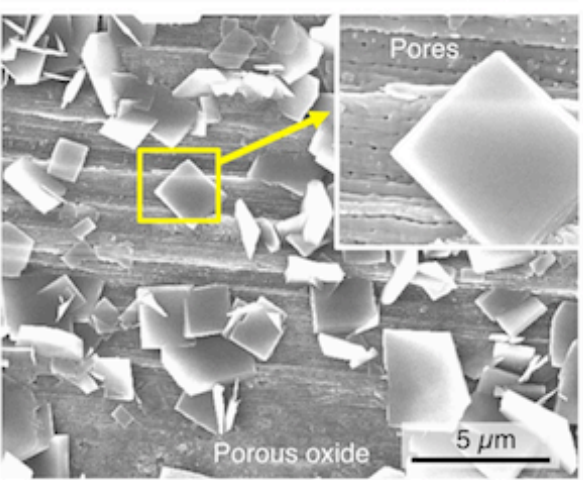

Fig. 10 
a)

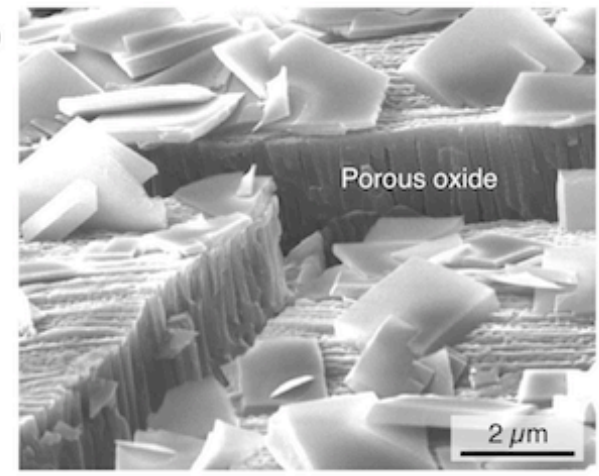

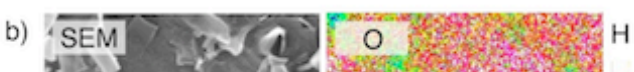

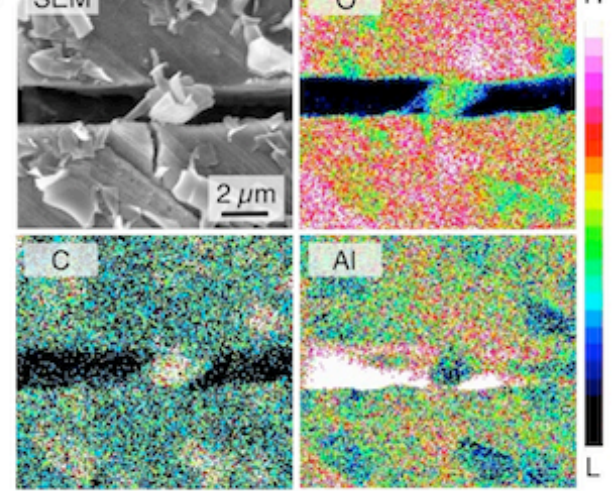

Fig. 11 